are small. Two cases of rheumatoid arthritis showed the lack of cortical bone suggestive of erosion. This study indicates the need for more careful appraisal of normal radiological anatomy in the hand, particularly in relation to rheumatoid lesions.

\section{Pin or Prosthesis?}

In 1931 Smith Petersen's triflanged nail converted an incurable fracture into one which surgeons-with characteristic optimism-at once considered straightforward. Experience has shown that fractures of the femoral neck can still be termed "insoluble," though nowadays this description should be reserved for displaced subcapital fractures.

Of the fractures at the upper end of the femur those occurring in the trochanteric region rarely cause problems. Fractures of the neck, on the other hand, present difficulties in reduction and internal fixation; it is not easy to ensure union, and half the subcapital fractures will undergo avascular necrosis. No less of a problem is the type of patient in whom these fractures occur. The victims are elderly women in the last decade of their life, many over 70 or 80 years old. They commonly suffer from multiple diseases at the time of injury, and, indeed, they are occasionally moribund when first admitted. Their skeletons are atrophic from senile osteoporosis- $50 \%$ to $75 \%$ of their bone may have disappeared. They are at an age when immobilization in bed is dangerous to life as well as function. Early mobility is essential. The mortality within three years of the fracture from other causes is very high. Furthermore, in the social pattern of Britain today many of these patients live alone, and even when all goes well with the fracture they never regain the independence needed to look after themselves. The numbers who need geriatric care overtax the resources available.

Fractures of the neck of the femur are still best treated by trifin nails. The very number of technical modifications of the original principle only confirms that problems remain. Pin and graft, low angled nail fixation, nails which compress the fracture site, a nail and plate, and many other devices have been tried and are still being devised.

The causes of failure in management were discussed in an excellent review ${ }^{1}$ by R. S. Garden, who showed that the completely displaced subcapital fracture was the major problem. Really good reduction makes it possible to place the nail easily and well, and it reduces the incidence of non-union and avascular necrosis. Poor reduction leads to a high rate of complications. But it is by no means easy to achieve a good reduction, and there has been a trend among some orthopaedic surgeons towards immediate excision of the femoral head in subcapital fractures, particularly in the elderly. They argue that many pinnings fail and require later prosthetic replacement-two operations and a long period of disability. Such a policy, as A. E. Nicoll pointed out, ${ }^{2}$ may lead to the same views as those of the Red Queen who had " only one way of settling all difficulties, great or small: off with his head."

The most telling argument against wholesale decapitation has perhaps been that half of the patients with subcapital fractures have normal hips after pinning. But G. A. Hunter, ${ }^{3}$

\footnotetext{
1 Garden, R. S., fournal of Bone and foint Surgery, 1961, 43B, 647 Nicoll, E. A., Fournal of Bone and foint Surgery, 1963, 45B, 239.

Hunter, G. A., British fournal of Surgery, 1969, 56, 229.

Catto, Mary, fournal of Bone and foint Surgery, 1965, 47B, 749.
}

writing from the accident service of the Radcliffe Infirmary, Oxford, has recently compared the results of treatment in two groups of patients, 94 receiving prosthetic replacement and 92 internal fixation. Prosthetic replacement came out poorly. In six patients prostheses dislocated, eight had deep wound infections (compared to none in the pinning series); embolism, myocardial ischaemia, and pneumonia were all more prevalent and more often fatal. Unfortunately any strict comparison between the two groups is affected by the difference in their average ages-79 for the prosthesis group and 73 for the others.

The functional results in survivors were definitely better in those pinned. In the pinning series 20 patients developed avascular necrosis and had secondary prosthetic replacement, but they did no less well than those treated primarily with a prosthesis. It is clear that primary prosthetic replacement gives neither as good an average result nor fewer complications in the aged, though it is a great advance in those in whom the pin has failed or avascular necrosis has occurred.

The most stubborn problem in this field is the occurrence of avascular necrosis, and despite many attempts by isotope studies and other techniques it is still not possible to identify a dead head before pinning. Mary Catto ${ }^{4}$ has shown how incompletely and variously the head may be ischaemic, so this problem will not be easy to solve. No satisfactory prospective study of the results of varied modes of treatment has yet been published. But surely the best line of attack is to intensify research into the cause, cure, or prevention of senile osteoporosis. In a community of half a million this " disease" costs approximately $£ 100,000$ a year for fractures of the femur alone. The amount spent on research into osteoporosis is in comparison pitiable.

\section{Hepato-renal Syndrome}

Renal failure is a common accompaniment of several forms of liver disease. Although the term " hepato-renal syndrome" does nothing to explain the reasons for the association between these conditions, it may nevertheless be worth retaining as a reminder that this dangerous complication can develop.

Renal failure is certainly a complication of terminal cirrhosis, ${ }^{1}$ though precisely why is not known. Structural changes in the kidney may sometimes be a cause of it, ${ }^{2}$ but the major cause is more likely to be haemodynamic. In particular, recent work has suggested that the failure may be due to overperfusion of medullary as compared with glomerular tissue. $^{3}$ Diuretic drugs may aggravate the condition, and ethacrynic acid may raise the level of blood urea. ${ }^{4}$ In other diseases the renal lesion may be a part of a general cellular damage in organs other than the liver. An example is poisoning by carbon tetrachloride or other drugs; another is the

Hecker, R., and Sherlock, S., Lancet, 1956, 2, 1121

Schroeder, E. T., Shear, L., Sancetta, S. M., and Gabuzda, G. J., American fournal of Medicine, 1967, 43, 887.

3 Saloman, M. I., et al., Archives of Internal Medicine, 1965, 115, 704.

- Sherlock, S., Senewiratne, B., Scott, A., and Walker, J. G., Lancet, 1966, 1, 1049.

5 Jones, E. A., Crowley, N., and Sherlock, S., 1967, Postgraduate Medical fournal, 43, Supplt. 7.

6 Williams, R. D., Elliott, D. W., and Zollinger, R. M., Archives of Surgery, 1960, 81, 334.

'Dawson, J. L., British fournal of Surgery, 1965, 52, 663.

8 Dawson, J. L., and Stirling, G. A., Archives of Pathology, 1964, 78,

254 .
Antoine, B., and Neveu, T., fournal of Laboratory and Clinical Medicine, 1968, 71, 101. 
involvement of several organs in patients with chronic active hepatitis probably due to diffuse immunological damage. Weil's disease and renal damage due to septicaemia-common in cirrhotic patients on immunosuppressive or corticosteroid therapy ${ }^{5}$ - are also causes of combined renal and liver failure.

A rather important relationship is to be noted between obstructive jaundice and renal failure, for in this situation damage to the kidneys may be preventable. Jaundiced patients are more susceptible than the average to hypotension and renal damage after operations. ${ }^{6}$ The danger is directly proportional to the level of the serum bilirubin. ${ }^{7}$ It has been suggested that infusions of mannitol ${ }^{8}$ before operation may prevent this complication, because experimental evidence shows that the kidneys of animals in which the bile duct is ligated resist change if mannitol is given. This suggests that renal ischaemia is secondary to a primary change in the kidneys.

An experimental study, published at page 229 of the B.M.7. this week by Mr. J. L. Dawson and his colleagues, who have done much of the work in Britain on this important association, shows that the susceptibility of the jaundiced kidney to postoperative ischaemic damage may be related to the nature of the retained bile pigment. They compared two strains of rats. The Gunn rat can produce only unconjugated bilirubin because of a congenital deficiency of an enzyme (glucuronyl transferase). It is not nearly so susceptible to renal change as is the normal, Wistar, strain, and these workers found there was no more evidence of renal damage in the operated Gunn rats after ligation of the bile duct than in the control group of Gunn rats. The villain of the piece therefore seems to be conjugated bilirubin, for it is the only component of bile that is known to differ between the two strains of rats. Moreover, bilirubin glucuronide is the only form found in the fluid in renal tubules, and it may be toxic even in the absence of is haemia. ${ }^{9}$ It seems likely, however, that bilirubin glucuronide is deconjugated in the kidney to produce bilirubin.

Can these results be applied to man? If so, how can the toxic effects of conjugated bilirubin on renal tubules be modified ? Mannitol merely prevents the secondary ischaemic change. These problems are clearly of importance to the management of the jaundiced patient before operation.

\section{L-Dopa in Parkinsonism}

The amount of melanin in the substantia nigra is reduced in patients with Parkinsonism, and biochemical research has shown that in melanocytes the amino acid tyrosine is hydroxylated to dihydroxyphenylalanine (dopa), a precursor of dopamine. Numerous authors, including $\mathrm{H}$. Ehringer and $\mathrm{O}$. Hornykiewicz, ${ }^{1}$ have shown that in patients suffering from this disease the concentration of noradrenaline and dopamine (3-hydroxytryptamine) is considerably reduced in the nuclei of the extrapyramidal system. So the use of dopa and its derivatives as a therapeutic agent in Parkinsonism seemed to to be a logical extension of this biochemical work, and in 1962 W. Birkmayer and Hornykiewicz ${ }^{2}$ found that dopa successfully controlled certain of the clinical manifestations of the disease.

Since then the picture has been somewhat clouded by varying reports from different centres. This has been partly due to the fact that many authors have used D,L-dopa, while others lave used the L-isomer in a level of dosage which might now be considered inadequate. However, as a recent report by G. C. Cotzias, P. S. Papavasiliou, and R. Gellene ${ }^{3}$ has shown, there can now be no reasonable doubt that many patients with Parkinsonism may be improved substantially by the administration of L-dopa. They treated 28 patients over periods of up to two years, and of these 20 were substantially improved. They began by giving $100 \mathrm{mg}$. three times a day, and cvery two to four days the dose was increased by $200-$ $300 \mathrm{mg}$., though some patients could tolerate increments of only $50 \mathrm{mg}$. per day. The maximum therapeutic effect and the maximum tolerated dose varied from individual to individual, but normally fell within the range of $3 \mathrm{~g}$. to $16 \mathrm{~g}$. daily. Perhaps the most exciting outcome of this and other similar carefully conducted trials ${ }^{4}$ has been the demonstration that the more disabling clinical manifestations, such as akinesia-which is not improved and is even sometimes worsened by surgery or by standard drug treatment-may be dramatically relieved by the use of this drug. Improvement was also seen in speech, in swallowing, and in reduction of salivation, and there was general improvement in posture, gait, and facial expression. On the other hand features of the Parkinsonian syndrome such as tremor, which respond best to stereotaxic surgery, are little improved by L-dopa.

Granulocytopenia, previously encountered in patients treated with D,L-dopa ${ }^{5-7}$ was not observed in this series of patients treated with the $\mathrm{L}$-isomer alone. The most important side-effects were nausea and vomiting, which could usually be prevented by a slow, gradual increase in dosage or perhaps by the concurrent administration of antihistamine agents. Behaviour disorders, sleeplessness, and involuntary movements, including myoclonus, chewing or gnawing movements, and choreiform movements of the limbs, were seen in some patients, but these often resolved when the dosage of the drug was decreased, though occasionally they necessitated its complete withdrawal.

The evidence now seems convincing that L-dopa is a therapeutic agent which is likely to constitute a major advance in the management of Parkinsonism, and that it is probably most effective in those patients whose disease is not significantly influenced by currently available surgical and pharmacological methods of treatment. Unfortunately this substance is at present available in Britain only as a chemical reagent ; it is expensive, and the preparation now in use may contain a greater percentage of impurity than would be acceptable to the Committee on the Safety of Drugs. The time has now come when drug companies should be encouraged to produce this substance in an acceptably pure form, so that a submission to the committee can be made in order that carefully designed trials of treatment can be initiated in selected centres. Many neurologists are already under pressure from their patients to prescribe this drug for them, and they are reasonably entitled to ask why it is not yet generally available in Britain.

\footnotetext{
1 Ehringer, H., and Hornykiewicz, O., Klinische Wochenschrift, 1960 38, 1236.

2 Birkmaver, W., and Hornykiewicz, O., Archiv für Psychiatrie und Nervenkrankheiten, 1962, 203, 560 .

3 Cotzias, G. C., Papavasiliou, P. S., and Gellene, R., New England Fournal of Medicine, 1969, 280, 337.

- Calne, D. B., Stern, G. M., Laurence, D. R., Sharkey, J., and Armitage, P., Lancet, 1969, 1, 744.

5 Cotzias, G. C., Van Woert, M. H., and Schiffer, L. M., New England fournal of Medicine, 1967, 276, 374.

- Hornykiewicz, O., Wiener klinische Wochenschrift, 1963, 75, 309.

Poirier, L. J., Sourkes, T. L., Bouvier, G., Boucher, R., and Carabin, S., Brain, 1966, 89, 37.
} 